\title{
EDITORIAL \\ As Manifestações Sociais, a Educação Crítica e a necessidade \\ de novas demandas para as \\ Políticas Educacionais
}

Há aqueles que lutam um dia; e por isso são muito bons; Há aqueles que lutam muitos dias; e por isso são muito bons;

Há aqueles que lutam anos; e são melhores ainda; Porém há aqueles que lutam toda a vida; esses são os imprescindíveis. (“Os que lutam”, de Berthold Brecht)

\section{Manifestações sociais, educação crítica e as políticas educacionais}

Apesar do título conferido a este editorial, não temos a pretensão de fazer análises mais detalhadas sobre as últimas lutas sociais ocorridas no Brasil, considerando a multidimensionalidade deste fenômeno e seus diversos matizes político-ideológicos. As manifestações foram travadas, de maneira intensa, nos meses de junho nas ruas das principais cidades brasileiras em meio ao caos urbano, e seus protestos ainda seguem seu curso de maneira menos intensiva. Tudo se passa na chamada "cidade do capital"1, que é 
construída sob a égide da divisão social espacial, isto é, da divisão de classes sociais, cujo processo e repercussão concreta, dá-se na perspectiva da reprodução e perpetuação do capitalismo.

A cidade do capital opera na dimensão da propriedade do solo e da renda fundiária no quadro urbano, focalizando a formação, realização e distribuição da mais-valia. Nestes meandros, as cidades são projetadas normalmente para a circulação de bens materiais, bens, serviços e mercadorias, cuja finalidade é atender apenas às demandas do capital e não aos interesses dos trabalhadores que efetivamente constroem as cidades com a força de trabalho humano. As cidades são projetadas para servir aos interesses burgueses, aos donos do capital. A mobilidade social de crianças, jovens, adultos, velhos e velhas trabalhadores está de forma incontestável associada à divisão de classes e ao mundo das mercadorias, cujo consumo, usufruto e monopólio dos espaços, equipamentos, bens e serviços de qualidade, que deveriam ser públicos, são destinados às elites e cerceados à classe trabalhadora empobrecida.

A epígrafe que inaugura este editorial pretende chamar a atenção para o fato de que, nessas mobilizações históricas de junho de 2013, estavam envolvidos milhares de brasileiros, que foram às ruas, após décadas de apatia social, mobilizados, fundamentalmente, pelas redes sociais, tendo em vista as lutas pelo "direito à cidade" ${ }^{2}$. O movimento teve como mote de lutas o emblemático protagonismo do Movimento Passe Livre e da Frente de Luta pelo Transporte Público de Qualidade e outras reivindicações. Além disso, os protestos também se insurgiram contra a corrupção e em favor de políticas públicas efetivamente de qualidade, tais como educação, saúde, mobilidade urbana, entre outras.

Neste limiar, os diversos sujeitos que estavam nas manifestações lutavam pelos mais diferentes motivos; lutavam, provavel- 
mente, "apenas por um dia", "por muitos dias" ou "por toda uma vida", conforme disse Brecht. Neste sentido, essas lutas sociais de massa assemelham-se aos ocorridos no mundo nos últimos anos em outros contextos políticos e sociais, como o Occupe Wall Street, a Primavera Árabe, a resistência na Síria, a ocupação da Praça Taksim, na Turquia, e, mais recentemente, a derrubada do presidente Mursi, do Egito.

Outro ponto digno de reflexão é a questão da despolitização desses movimentos, supostamente "espontâneos" e torna ambígua e controversa a organização política dos manifestantes unicamente pela via das redes sociais. Como ficou evidente, os protestos nas ruas do Brasil tiveram sua principal forma de organização por meio da internet, que, sob um certo ponto de vista da "aparência", pode transparecer e até se configurar como estratégias democráticas, descentralizadas e eficazes, proporcionadas pelas novas tecnologias digitais de comunicação. Nesses meandros, pôde-se ver milhares de brasileiros com suas mais diversas formas de organização para a vida em sociedade: sindicatos, associações, entidades, clubes, partidos, igrejas, grupos de hip-hop, teatro, poesia. Com efeito, não se pode olvidar que foram essas redes que se mobilizaram para produzir as manifestações pela redução da tarifa dos transportes públicos, trazendo para as ruas uma infinidade de grupos difusos com os objetivos e bandeiras também difusas. Esses sujeitos se organizaram fundamentalmente pelas redes sociais, que pode nos dar muitos elementos de análise social, mas não necessariamente reverberam a consistência política da mobilização ${ }^{3}$.

Quanto a esse respeito, talvez tivéssemos que relativizar um pouco esse elogio fetichizante do "pensamento mágico", para o qual as redes sociais são consideradas como único fator de organi- 
zação social e política, conforme a avaliação de Marilena Chauí ${ }^{4}$. A filósofa afirma que, diferentemente dos movimentos sociais e populares, os recentes protestos tiveram uma forma de convocação que as transformou em um movimento de massa, por intermédio da comunicação on-line dos jovens, mobilizando milhares de manifestantes nas ruas. De acordo com suas análises, trata-se de uma avaliação pautada no que ela chama de "pensamento mágico", que poderia se basear em uma análise mais dialética, pautada pela "negatividade" e não pela "positividade", conforme os seguintes pontos e argumentos grifados por nós para reflexão:

[...] a convocação foi feita por meio das redes sociais. Apesar da celebração desse tipo de convocação, que derruba o monopólio dos meios de comunicação de massa, entretanto é preciso mencionar alguns problemas postos pelo uso dessas redes, que possui algumas características que o aproximam dos procedimentos da mídia. (grifo nosso).

a. é indiferenciada: poderia ser para um show da Madonna, para uma maratona esportiva, etc. e calhou ser por causa da tarifa do transporte público; (grifos nossos).

b. tem a forma de um evento, ou seja, é pontual, sem passado, sem futuro e sem saldo organizativo porque, embora tenha partido de um movimento social (o MPL), (à medida que cresceu passou á recusa gradativa da estrutura de um movimento social para se tornar um espetáculo de massa). Dois exemplos confirmam isso: a ocupação de Wall Street pelos jovens de Nova York e que, antes de se dissolver, se tornou um ponto de atração turística para os que visitavam a cidade; e o caso do Egito, mais triste, pois com o fato das manifestações permanecerem como eventos e não se tornarem uma forma de auto-organização política da sociedade, deram ocasião para que os poderes existentes passassem de uma ditadura para outra); (grifo nosso). 
c. assume gradativamente uma dimensão mágica, cuja origem se encontra na natureza do próprio instrumento tecnológico empregado, pois este opera magicamente, uma vez que os usuários são, exatamente, usuários e, portanto, não possuem o controle técnico e econômico do instrumento que usam - ou seja, deste ponto de vista, encontram-se na mesma situação que os receptores dos meios de comunicação de massa. (grifo nosso).

A dimensão é mágica porque, assim como basta apertar um botão para tudo aparecer, assim também se acredita que basta querer para fazer acontecer. Ora, além da ausência de controle real sobre o instrumento, a magia repõe um dos recursos mais profundos da sociedade de consumo difundida pelos meios de comunicação, qual seja, a idéia de satisfação imediata do desejo, sem qualquer mediação; (grifo nosso).

d. a recusa das mediações institucionais indica que estamos diante de uma ação própria da sociedade de massa, portanto, indiferente à determinação de classe social; ou seja, no caso presente, ao se apresentar como uma ação da juventude, o movimento assume a aparência de que o universo dos manifestantes é homogêneo ou de massa, ainda que, efetivamente, seja heterogêneo do ponto de vista econômico, social e político, bastando lembrar que as manifestações das periferias não foram apenas de 'juventude' nem de classe média, mas de jovens, adultos, crianças e idosos da classe trabalhadora. (grifos nossos).

Apesar de todo esses argumentos de Marilena Chauí, em termos da relativização do papel da mobilização da juventude pelas redes sociais, talvez tenhamos de admitir também que a presença de difusos interesses nas ruas expôs as contradições, expondo, assim, a necessidade de reformas radicais nas políticas sociais e públicas brasileiras, em especial, transporte, saúde, educação, além do re- 
púdio à corrupção. Com efeito, esses movimentos reacenderam o fogo das lutas sociais em favor da conquista por direitos civis e políticos na perspectiva teleológica da "cidadania como um processo em construção"s. O fato dos jovens e a população em geral irem às ruas, mostrando a força popular contra os aumentos dos preços dos transportes públicos, tem um significado concreto e simbólico na perspectiva de incentivo às diversas gerações contra a lógica do capital nas diversas dimensões da vida cotidiana. Esse aspecto deve ser ressaltado considerando que, inicialmente, pareciam apenas lutar pela por $\mathrm{R} \$ 0,20$ no rebaixamento da tarifa do transporte coletivo, mas depois o movimento foi ganhando força a partir das estratégias forjadas pelo emblemático protagonismo do Movimento Passe Livre e da Frente de Luta pelo Transporte Público de Qualidade. Assim, não se pode olvidar que ponto de partida desses protestos está diretamente ligado à questão da mobilidade urbana e o aumento do preço da passagem, constituindo-se, portanto, de uma retomada das lutas sociais pela juventude brasileira e por difusos grupos informais e movimentos sociais organizados.

As mobilizações tem o potencial de lançar as bases para construir força na sociedade brasileira suficientes para retomar a luta pelas reformas estruturais. ${ }^{6} \mathrm{O}$ que era uma luta específica se tornou uma indignação generalizada. Essas revoltas tem origem no desmonte dos serviços públicos essenciais (saúde, educação, segurança etc.). A amplitude da revolta popular exigiu a imediata apresentação e a execução de propostas definidas pelo poder público. Entre as muitas bandeiras içadas, o combate à corrupção, $o$ incremento da saúde, a melhoria do ensino, na crescente destinação para os ricos, os grandes bancos e os monopólios privados dos recursos que deveriam ser investidos nessas áreas e, com ênfase, $o$ repúdio e a consequente retirada da PEC $37^{7}$. 
As manifestações tiveram como pano de fundo, e objeto de protestos, os gastos com os Megaeventos Esportivos no Brasil e seus supostos "legados", cujo financiamento envolve a utilização de verbas públicas na construção das arenas esportivas exigidas pelo "padrão FIFA", em um país marcado pelas profundas desigualdades sociais, conforme as "palavras de ordem" dos manifestantes. Neste âmbito, também estão as promessas de melhorias na mobilidade urbana, dos transportes, enfim, da qualidade de vida da população. Durante a realização da Copa das Confederações, era comum ver placas alusivas à ineficácia das políticas públicas, como por exemplo: "Da Copa eu abro mão! Quero Saúde e Educação" e "Queremos escolas Padrão FIFA". Viam-se os gritos e cartazes indignados dos manifestantes com os seguintes protestos: "Menos Copa e mais serviços públicos de qualidade", "Chega de dinheiro público gasto na Copa", "Pelo fim das remoções de famílias pobres para as obras da Copa", "Fim das privatizações e terceirizações", "Defesa incondicional do SUS público, gratuito, estatal, universal e de qualidade", "Educação pública, gratuita e de qualidade em todos os níveis", "10\% do PIB para a educação pública, já!", "Desmilitarização da polícia e dos bombeiros" e "Não à criminalização e repressão aos movimentos sociais e sindicais".

O conteúdo dessas reivindicações, contidos nas vozes, faixas e cartazes dispersos pela multidão nas ruas, apesar do incentivo e tentativa de desqualificação e despolitização dos movimentos sociais, orquestrados pela "espetacularização" da mídia burguesa por mais Ibope e pela direita oportunista, são de suma relevância para se pensar as relações entre Estado e Sociedade, a partir das demandas e reivindicações sociais. Na esteira desse fenômeno, insurge-se a necessidade de repensar a relação entre Ciência e Política e, isto 
porque, apesar das contradições e paradoxos evidenciados durante as manifestações, temos que, daqui por diante, refletir com mais radicalidade sobre a importância dessas manifestações para as mudanças essências e necessárias no modo de fazer política e, é claro, para efetiva construção de políticas públicas e sociais efetivamente populares e democráticas. Em suma, no plano simbólico-real, as manifestações anunciaram para os políticos e intelectuais a necessidade iminente da reavaliação das políticas públicas e sociais, em especial, das políticas educacionais.

Diante dessas evidências emergidas nas ruas, o tema das políticas educacionais passa a se constituir em um ponto de pauta permanente nas agendas dos debates, sobretudo, em tempos de crise cíclica do capital e, consequentemente, na Educação ${ }^{8}$. Neste sentido, torna-se imprescindível continuar no plano acadêmico e sindical, continuar o debate e a luta pelos royalties do "Pré-Sal" para a educação, no sentido dos reclamos populares nas ruas pela "Educação pública, gratuita e de qualidade em todos os níveis" e dos “ $10 \%$ do PIB para a educação pública, já". Isto requer que continuemos a realizar um debate crítico no interior da comunidade acadêmica, isto é, nos grupos e linhas de pesquisa dos programas de pós-graduação, nos GT’s da ANPEd e outros eventos. Para além disso, devido à contundência das manifestações do mês de junho e julho dos grupos informais e dos movimentos sociais organizados (centrais sindicais) ${ }^{9}$, convém aprofundar o debate e as pesquisas, tendo como eixo a relação teoria e prática, a conjuntura nacional e internacional e as demandas e proposições desses movimentos em termos de políticas públicas em geral e, particularmente, de políticas educacionais.

Trata-se de uma emergência epistemológica e político-ideológica, diante dos profundos e radicais problemas da crise do capital 
e, consequentemente, das suas ingerências nefastas e destrutivas nas políticas públicas em geral e, sobretudo, nas políticas educacionais. A atual crise internacional do capitalismo neoliberal tem suscitado a retomada do papel do Estado e o questionamento da supremacia do mercado e seus agentes. Essa crise do capital e suas ingerências sobre os Estados nacionais não pode ser vista separada do desmonte nas políticas sociais e públicas dos chamados países "periféricos" e "dos emergentes". Todo esse processo está diretamente articulado às políticas e planos de ajuste do Banco Mundial e do FMI. Está vinculado aos "planos de ajuste estrutural” dessas instituições internacionais, mediante seus esquemas e "pacotes intervencionistas" e de "estabilização econômica" nos Estados nacionais. Esses planos intervencionistas, conforme Chossudovsky ${ }^{10}$, terminam por aumentar a subordinação destes para com essas agências multilaterais, culminando, assim, com o aumento abissal da pobreza global, deterioração da classe trabalhadora, das políticas públicas e sociais e, consequentemente, das desigualdades sociais e escolares.

\section{O dossiê: Educação crítica}

As reflexões supramencionadas sobre as manifestações do mês de junho e suas relações com políticas educacionais trazem consigo, conforme já mencionada, a necessidade de outras formas de reflexão sobre as políticas educacionais; trazem a necessidade de se pensar uma "educação crítica", ou seja, uma "educação para além do capital". A educação pensada nestes termos deve ser compreendida com o objetivo de pensar uma alternativa educacional que 
seja formulada do ponto de vista da emancipação humana, e não das determinações e limitações que o sistema do capital impõe também sobre a produção vida e das ideias. Nestes termos, há a possibilidade de se repensar a fundamentação teórica da "educação crítica”, em cujo âmago se circunscrevem as diversas posições e tendências epistemológicas acerca da pedagogia, em especial, da "pedagogia crítica". Sendo assim, talvez devêssemos retomar, crítica e propositivamente, as diversas políticas educativas de "esquerda", implementadas por diversos governos estaduais e municipais, nomeadamente, as "pedagogias da educação popular", as "pedagogias da prática" e a "pedagogia crítico-social dos conteúdos". Isto posto, poderíamos, quem sabe, pensar em uma educação "para além do capital”, que pudesse trazer em seu bojo a fundamentação teórica da "pedagogia histórico-crítica" fundada nos aspectos filosóficos, históricos, econômicos e político-sociais. Nessas bases, poderia se pensar em "[...] seguir as trilhas abertas pelas relevantes e radicais investigações desenvolvidas por Marx sobre as condições históricas de produção da existência humana que resultaram na forma da sociedade atual dominada pelo capital." ${ }^{11}$ Isto implicaria em pensar os processos educativos em um sentido mais amplo, que vai além dos níveis de ensino ou sistemas escolares; isto é, a educação como o processo vital de existência do homem, isto é, aquilo que caracteriza a sua especificidade de "ser social", a saber, a capacidade de conhecer, de ter ciência do real e de, portanto, transformá-lo de forma consciente. $^{12}$

O dossiê desta edição tem como tema a "Educação Crítica"13, sob a organização do nosso convidado especial Luís Armando Gandin, professor de Sociologia da Educação da Universidade Federal do Rio Grande do Sul e editor das revistas Currículo sem Fronteiras e 
Educação e Realidade. O dossiê inicia com um texto introdutório sobre a "Educação Crítica - pressupostos e aplicação em pesquisas", no qual ele afirma que "[...] a Educação Crítica tem uma longa tradição de contribuição às pesquisas, ao entendimento dos fenômenos educacionais de nosso tempo e à intervenção nestes fenômenos. Muitos pesquisadores e estudiosos têm buscado explicar e aplicar a concepção crítica em educação." Em seguida, o autor apresenta as pesquisas dos autores convidados para o dossiê, iniciando com os excelentes textos do pesquisador norte-americano Michael W. Apple (University of Wisconsin-Madison) e Marco Mello, Rodrigo Ramos, Simone Costa Moreira, Graziella Souza dos Santos, Tiago Cortinaz e Iana Gomes de Lima (UFRGS).

O debate instaurado por este grupo de autores é de suma relevância, tendo em vista as reflexões epistemológicas sobre a problemática em questão. Em linhas gerais, a pedagogia crítica e os estudos educacionais críticos "[...] buscam expor o modo como as relações de poder e desigualdade (social, cultural, econômica), em sua miríade de combinações de formas e complexidades, manifestam-se e são postas em questão na educação formal e informal das crianças e adultos." Mais ainda é preciso levar em conta uma compreensão mais robusta da pedagogia crítica e da Educação Crítica, que se baseia cada vez mais na percepção e importância das múltiplas dinâmicas que sustentam as relações de exploração e dominação na sociedade capitalista. Sendo assim, temas que dizem respeito à política de redistribuição (processos e dinâmicas econômicas de exploração) e à política do reconhecimento (lutas culturais contra a dominação e lutas pela identidade), portanto, precisam ser consideradas em conjunto ${ }^{14}$. Isto significa considerar a multidimensionalidade dos fenômenos educativos, no que 
concerne às relações imbricadas entre classe, gênero, raça/etnia, cultura e geração, de tal sorte que se possa, à medida do possível, articular, por exemplo, o debate entre desigualdades sociais (classe) e diversidades socioculturais (gênero, raça/etnia, cultura, geração e outras categorias analíticas. Está em pauta um grande desafio para aqueles intelectuais que, no âmbito de seus gabinetes nas universidades, estão atentos as "vozes que vem das manifestações nas ruas das cidades brasileiras e do mundo", conforme uma das "oito tarefas da pesquisa e da ação da educação crítica", que visam "testemunhar a negatividade" e recapturar a memória coletiva do trabalho pedagógico que seja genuinamente contra-hegemônico:

Os educadores críticos devem também agir juntamente com os movimentos sociais apoiados por seu trabalho ou com os movimentos contra os pressupostos direitistas e com as políticas que analisam criticamente. Assim a formação acadêmica em educação crítica ou pedagogia crítica de fato implica tornar-se um 'intelectual orgânico' no sentido gramsciano do termo (GRAMSCI, 1971). Devemos participar e dar nosso conhecimento especializado aos movimentos que se voltam às lutas por uma política de redistribuição e por uma política de reconhecimento. Também implica aprender com esses movimentos sociais. Isso quer dizer que o papel da 'intelligentsia despreocupada' (Mannheim, 1936), alguém 'que vive na sacada' (Bakhtin, 1968), não é um modêlo apropriado. Conforme lembra Bourdieu (2003, p. 11), nossos esforços intelectuais são cruciais, mas eles 'não podem ficar observando tudo ao lado, de maneira neutra e indiferente, das lutas nas quais o futuro da humanidade está em jogo.' ${ }^{15}$

\section{O conteúdo das diversas sessões}

A sessão "artigos" contém diversos trabalhos, frutos de trabalhos inéditos de investigações realizadas por grupos de pesquisa, 
sínteses de dissertações de mestrado, tese de doutorado ou ainda artigos que são considerados desdobramentos de pesquisas desse teor. Em linhas gerais são artigos de natureza crítica que abordam temas relativos às políticas educacionais, como por exemplo, os textos: "Omissões, inconsistências e erros na descrição da legislação educacional" (Nicholas Davies/UFF); "Adolescentes em tempo integral - significados de passar o dia na escola" (Catherine Monique de S. Hermont/UFMG); "Ações afirmativas na educação superior: mulheres negras cotistas e mobilidade social" (Ana Luisa Alves Cordeiro/ (UCDB).

No que se refere à problemática "trabalho e educação", pode-se recorrer ao artigo "O trabalho como centralidade da condição juvenil" (Luiz Henrique Roberti/UFMG) e o artigo "Educación y trabajo: ¡un binomio que suscita ideas para ser libres y dignos de verdad!" do pesquisador peruano Enrique M. Jaramillo García.

Em seguida, são apresentados dois trabalhos baseados em concepções críticas à psicologia e à pedagogia: "Crítica da constituição da Psicologia como ciência: contribuições da Teoria Crítica da Sociedade" (Abel Silva Borges/UFSC); "A pedagogia libertadora e a psicologia histórico-cultural: dialogando educação e desenvolvimento humano" (Solange Maria Alves/UFFS).

A questão da infância é abordada, tomando como eixo algumas problemáticas da educação Infantil e da formação, quais sejam: "A identidade docente aos olhos das crianças" (José Douglas Alves dos Santos e Marizete Lucini/UFS); "Gênero, tamanho e desempenho: elementos centrais das ações e relações sociais de crianças pequenas" (Márcia Buss-Simão/UFSC); "O burn-out entre professores da educação infantil" (Rita Geovane Rosa Stumpf/Unisinos).

Outro bloco de artigos traz para reflexão sobre a importância da estética do cinema no processo de formação, a saber: "Cine- 
ma, participação estética e imaginação" (Monica Fantin/UFSC); "O cinema como prática didático-pedagógica no ensino jurídico" (Ana Carla de Oliveira Mello Costa Pinho e Zeila de Brito Fabri Demartini/ Unimesp). A sessão encerra com o artigo "Educação do campo e etnomatemática: um diálogo entre Deleuze, Guattari e Wittgenstein" (Claudia Glavam Duarte e Leonidas Roberto Taschetto/UFSC).

Na sequência dos artigos de demanda contínua, a sessão "Resenhas" está contemplada com o texto "Educação e Cinema" (Valeska Fortes de Oliveira e Fernanda Cielo), contribuindo para as reflexões sobre cinema e educação junto aos dois textos publicados na sessão de artigos. O "Fórum de Permanente de Debate sobre a Educação Básica" retoma o tema da alfabetização, sempre atual e pertinente, com o texto "Alfabetizar letrando com sentido e significado para a vida dos educandos" (Leusa Fátima Lucatelli Possamai/Udesc).

O espaço intitulado "Caminhos Abertos", pensado para fazer relações da graduação com a pós-graduação, além de relatos de experiência com iniciação científica e projetos de extensão, traz as seguintes contribuições: "Matemática: (re)significando saberes, construindo cidadania" (Tassiani Jorge de Oliveira, Thiago Henrique Mascarello, Cláudia Maria Grando, Rosemari Ferrari Andreis/Unochapecó). Por fim, o texto "Inclusão na Educação Infantil: a experiência de uma criança com Síndrome de Down" (Juciele Luisa Michalak Speroto e Dariane Carlesso/UFSC).

Para fechar esta edição, apresentamos finalmente a sessão “Textos Audiovisuais", cujo objetivo é apresentar as diversas linguagens que se circunscrevem na perspectiva da relação entre mídia e educação, nomeadamente as tecnologias de informação comunicação 
(TIC’s). Ela traz para reflexão o documentário "Carne e Osso", organizado por Leonardo Sakamoto (2011), sob a direção de Caio Cavechini e Carlos Juliano Barros. O conteúdo do filme aborda, de maneira incisiva e dramática, a situação desumana do mundo do trabalho dos frigoríficos do Brasil, principalmente no que diz respeito aos acidentes de trabalho nesses meandros. Trata-se de uma problemática de suma relevância e atual, considerando que os frigoríficos ganham mercado em todo o mundo, e, na esteira deste sucesso, estão histórias pouco conhecidas de trabalhadores afastados por jornadas de trabalho intensas, penosas e repetitivas. O filme traz em seu bojo o estímulo a repensar a relação entre trabalho e educação e, fundamentalmente, a "saúde do trabalhador", tanto em mundos de trabalho desta natureza, quanto dos trabalhadores em geral e pontualmente a saúde dos professores ("o mal-estar docente"), que estão acometidos de doenças oriundas do trabalho "intensificado" nas escolas e universidades brasileiras.

Para encerrar e sermos coerentes com a linhas com o título do editorial, deixamos para a reflexão dos leitores mais um poema de Berthold Brecht, intitulado "Sobre a atitude crítica":

Sobre a atitude crítica A atitude crítica

É para muita não muito frutífera Isto porque com sua crítica

Nada conseguem do Estado Mas o que neste caso é atitude infrutífera

É apenas uma atitude fraca

Pela crítica armada Estados podem ser esmagados A canalização de um rio $O$ enxerto de uma árvore A educação de uma pessoa (grifos nossos) 


\section{A transformação do Estado (grifos nossos)}

Estes são exemplos de atitude frutífera

E são também

Exemplos de arte.

Maurício Roberto da Silva (Editor da Revista Pedagógica)

\section{Notas}

${ }^{1}$ LEFEBVRE, Henri. A cidade do capital. Rio de Janeiro: DP\&A, 1999. Cap. 2, p. 29-73. LEFEBVRE, Henri. O direito à cidade. São Paulo: Centauro, 2001.

${ }^{2}$ LEFEBVRE, Henri. O direito à cidade. São Paulo: Centauro, 2001.

${ }^{3}$ Editorial Para onde vai o governo. In: LE MONDE DIPLOMATIQUE. Por uma vida sem catracas, ano 6, n. 72, jul. 2013.

${ }^{4}$ CHAUÍ, Marilena. O inferno urbano e apolítica do favor, tutela e cooptação. Revista Teoria e Debate, 26 jun. 2013. Disponível em: <www.teoriaedebate.org. $\mathrm{br} />$.

${ }^{5}$ BOTELHO, André; SCHWARTZ, Lilia Moriz (Orgs.). Cidadania um projeto em construção: minorias, justiça e direitos. São Paulo: Claro Enigma, 2012.

${ }^{6}$ JORNAL BRASIL DE FATO, p. 2, 20 a 26 jun. 2013.

${ }^{7}$ Editorial da Revista Motrivivência: As lutas sociais, os megaeventos esportivos no Brasil, as políticas públicas e o "padrão FIFA", ano 25, n. 40, jun. 2013. Disponível em: <www.periodicos.ufsc.br $>$.

${ }^{8}$ Editorial As reflexões sempre pertinentes e necessárias sobre as políticas educacionais. Revista Pedagógica, ano 13, v. 2, n. 25, jul./dez. 2010.

9 Estamos nos referindo às manifestações de 11 de julho de 2013, em comemoração ao "Dia Nacional de Lutas", convocado pelas centrais sindicais e movimentos sociais.

${ }^{10}$ CHOSSUDOVSKY, Michel. A globalização da pobreza: impactos das reformas do FMI e do banco Mundial. São Paulo: Moderna, 1999. 
${ }^{11}$ SAVIANI, Dermeval. História das Idéias pedagógicas no Brasil. Campinas, SP: Autores Associados, 2008. p. 422.

${ }^{12}$ MÉSZÁROS, István. A educação para além do capital. São Paulo: Boitempo, 2005.

${ }^{13} \mathrm{O}$ autor é um dos organizadores, junto com Wayne Au e Michael Apple, do livro Educação Crítica: Análise internacional. Porto Alegre: Artmed, 2011.

${ }^{14}$ Fraser (apud APPLE, Michael; AU, Wayne; GANDIN, Luís. O mapeamento da Educação Crítica. In: Educação Crítica: Análise internacional. Porto Alegre: Artmed, 2011. p. 14.

15 APPLE, Michael; AU, Wayne; GANDIN, Luís. O mapeamento da Educação Crítica. In: APPLE, Michael et al. Educação Crítica: Análise internacional. Porto Alegre: Artmed, 2011. p. 14-16. 
